Dental Manifestations of Systemic Disease (Radiology in Clinical Diagnosis series)

By David H. Trapnell and J. E. Bowerman. Pp. 175, illustrated. London: Butterworths, 1973. £4.95.

The authors of this book have taken on the difficult task of writing for two different groups. This has produced an uncomfortable splitting of the levels at which they have directed their information. Some parts are annoyingly simple; others seem too rare to justify the space given to them. However, the need for such a book is unquestionable as many dental surgeons do not look beyond the teeth and jaws and few medical radiologists can interpret or recognize the more subtle changes around teeth.

The reproduction of radiographs in print is still not ideal and this detracts much of the value from books such as this. I feel that clearer films could have been used for the examples of normal anatomy. In view of the importance the authors attach to 'osteoporosis circumscripta' in Paget's disease a print of this stage of the disease would have been helpful. Although I appreciate the reason for not including the temporo-mandibular joint in this book perhaps the authors would reconsider it bearing in mind the difficulty many people have in interpreting changes in the joint seen on the various projections.

I would recommend this book to all radiologists, and to dental surgeons, particularly those preparing for the F.D.S.

\section{A Colour Atlas of Dermatology}

By G. M. Levene and C. D. Calnan. Pp. 368, illustrated. London: Wolfe Publishing Ltd, 1974. £5.50.

This book is compact, comprehensive and well produced. It consists in the main of well selected colour photographs. There is a good index and an introduction which gives the novice some idea of dermatological morphology and terminology and of the importance of history-taking and examination. Thereafter the conditions illustrated are listed in a way as satisfactory as any grouping can ever be, given the lack of adequate knowledge of aetiology. The survey is comprehensive, with pictures of many rare conditions. Many of the photographs are excellent and each is accompanied by a brief comment; each disease entity is prefaced by short notes on the condition. A few photographs are less good, or less well produced, and the quality of the colour is uneven. The vast majority, however, can be hailed with delight by a practising dermatologist as typical examples of the conditions in question.

The book is not a substitute for experience in the skin clinic but it should be useful for nurses, students and general practitioners. It may be of even more value to those such as junior hospital staff working for the M.R.C.P. or looking after dermatological beds, and general practitioners working as clinical assistants in dermatology.

\section{A Colour Atlas of Venereology}

By A. Wisdom. Pp. 349, illustrated. Wolfe Medical Atlases. London: Wolfe Medical Books, 1973. $£ 6.00$.

The author is to be congratulated not only on assembling this large collection of photographs but in covering, in a way with which few could find fault, a field where the disciplines of venereology, gynaecology and dermatology overlap. The aim of the book, which is achieved, is to concentrate on the common and hence important conditions.
There is a brief introduction, which deals with historytaking and examination; the need for clarity in communication is stressed. There follow good sections on the aetiology of common presentations in the male and female with several useful tabulated lists, and a brief but comprehensive account of techniques of examination. There is a good index. The material is grouped under sensible headings. Most of the photographs are of good quality. All the venereal diseases and all relevant skin diseases are adequately dealt with. The brief notes accompanying each section are unexceptionable. The book can be recommended unreservedly to all those who are non-specialists in venereology and who from time to time need a simple book of reference.

\section{Recent Advances in Surgery}

Edited by Selwyn Taylor. No. 8. Pp. 485, illustrated. Edinburgh and London: Churchill Livingstone, 1973. £3.50.

The reputation of 'Recent Advances in Surgery' under the editorship of Selwyn Taylor will ensure a welcome for this new edition and a perusal of the subject headings will further stimulate the interest of the surgeon, be he consultant or registrar. The latter, who may have an examination ahead, will welcome this opportunity of reading up-to-date reviews of general and specialized surgical topics by experts in their fields. There is much of concern for the general surgeon with chapters on such subjects as relief of pain, antibiotics in surgery, and reviews of the treatment of ulcerative colitis, haemorrhoids and peripheral vascular disease, while the chapters on carcinoma of the oesophagus, lung transplantation, complications of renal transplantation, surgery of hyperparathyroidism and others will acquaint him with what is current practice in the specialist fields. It is a commentary on the changed situation in which we are living that there should be a chapter on the surgery of civil violence, written by those who are performing it, almost daily, in Belfast.

This eighth edition, with its wide-ranging selection of surgical topics, maintains the reputation of this work.

\section{Current Practice of Biliary Surgery}

By Gabriel A. Kune. Pp. 419, illustrated. Edinburgh: Churchill Livingstone, 1973. $£ 8.00$.

Dr Kune is to be congratulated on producing this excellent little monograph. Even those with considerable experience in the practice of biliary surgery will find much to interest them and for the Registrar who is still learning about the subject this book will be invaluable. In particular, the chapters concerning the anatomy of the biliary tree and its abnormalities will be found most valuable. Chapters on cholangiography, their indications and contra-indications, are particularly well done, as is the chapter on the management of obstructive jaundice. The illustrations are excellent and the reproduction of his radiographs are of very high quality. There is much useful information about drainage of the biliary tree.

Like all text books of today it is expensive but the excellence of the monograph makes it well worth the price. It is a book which should find itself on the bookshelves of all medical libraries and those surgeons who practice biliary surgery. 